\title{
Foreword from the President of Sacramento State
}

\author{
Dear Colleagues,
}

The Journal of Transformative Leadership and Policy Studies (JTLPS) is a peer-reviewed Journal sponsored by the California State University Chancellor's Office and the CSU's 16 Education Doctorate programs. I encourage you to read and share Volume 8.2 with your colleagues and scholarly communities.

Volume 8.2 highlights the importance of leadership and the impact of leadership development in the transformation of educational institutions. Each article has a unique perspective, and collectively, the volume emphasizes the vital role of leadership, innovation, and change in institutional equity initiatives.

Real institutional change requires transformational leadership, and transformational leadership requires critical thinking and a willingness to upset the status quo. The articles in Volume 8.2 demonstrate the significance of implementing transformative leadership strategies for educators and administrators. The authors draw on their own experiences as educational practitioners to suggest recommendations on how to improve institutional effectiveness and equity and to create meaningful and lasting changes.

Critical insights to help us move toward a brighter future are offered in this volume - a future where we not only meet our students' basic needs, but where our students' greatest potentials are also realized. I encourage you to utilize Volume 8.2 as both a leadership tool and a guide for how to think about and instigate institutional change.

Respectfully,

\section{Robert S. Nelsen}

President

California State University, Sacramento 